\title{
Enseñando significados y representaciones culturales: su importancia en la salud de los trabajadores migrantes
}

\author{
Teaching Cultural \\ Meanings and \\ Representations: Why It \\ is Important for the Health \\ of Migrant Workers
}

\author{
Ensinando significados \\ e representações culturais: \\ sua importância na \\ saúde dos trabalhadores \\ migrantes
}

Louise M. Greathouse Amador* Orcid: https://orcid.org/0000-0002-7057-9068

Adriana Contreras Juárez** Orcid: https://orcid.org/0000-0002-9201-3006

Patricia Preciado Lloyd*** Orcid: https://orcid.org/0000-0002-2048-0756

\section{Para citar este artículo}

Greathouse Amador, L., Contreras Juárez,

A. y Preciado Lloyd, P. (2019). Enseñando significados y representaciones culturales: su importancia en la salud de los trabajadores migrantes. Folios, 49, 123-135. doi: 10.17227/Folios.49-9399
* Licenciada en Lingüística Aplicada a la Enseñanza, Universidad de Texas en Arlington; maestra en Lingüística Aplicada a la Enseñanza por la UDLA; doctora en Sociología ICSYH-BUAP. Profesora Investigadora de tiempo completo en el Instituto de Ciencias Sociales y Humanidades "Alfonso Vélez Pliego" (ICSYH)-BuAP, en el Posgrado de Ciencias del Lenguaje.

Correo electrónico: louisa33@mac.com

* Licenciada en Enseñanza de Lenguas Extranjeras en el área de Inglés por la Universidad Autónoma Benito Juárez de Oaxaca; maestra en Lingüística Aplicada por la BUAP. Actualmente profesora independiente de lenguas.

Correo electrónico: adrianalanguages@gmail.com

*** Licenciada en la Enseñanza de Lenguas Extranjeras por la BUAP; maestra en Ciencias del Lenguaje por la BUAP; Sociolingüística de la Enseñanza Básica Indígena Bilingüe por la UPN, Doctora en Lingüística Aplicada por Macquarie University. Integrante del Posgrado en Ciencias del Lenguaje del Instituto de Ciencias Sociales y Humanidades "Alfonso Vélez Pliego" de la BuAP.

Correo electrónico: patriciapreciado@hotmail.com 


\title{
Resumen
}

El presente ejercicio transdisciplinario presenta las dificultades que enfrentan los hablantes hispanos legales 0 ilegales que viven en otros países al solicitar atención médica. Teniendo en cuenta que tanto los significados de las palabras como las representaciones culturales de las emociones son de gran importancia para proporcionar la atención médica adecuada, este artículo se refiere a la emoción del enojo y su relación con la salud y la enfermedad. De manera que la lengua misma y el bagaje cultural sobre esta emoción y su repercusión en la salud se estudian mediante un recorrido por la medicina contemporánea y sus antecedentes hipocráticos, la medicina indígena y la medicina moderna. Para la población participante de este estudio, la representación social del enojo tiene una relación con el equilibrio térmico corporal, así, desde el punto de vista de varones y mujeres, se presentan algunos resultados sobre la relación del enojo con la salud y la enfermedad. Estos concluyen la necesidad de un entendimiento cultural sobre las enfermedades de los mexicanos a través de las oportunidades en la vida cotidiana de quienes brindan la atención médica.

\section{Palabras clave}

salud; enfermedad; hablantes hispanos; atención médica; cultura; enojo

\begin{abstract}
This transdisciplinary work presents the difficulties faced by legal or illegal Spanish speakers living in other countries when requesting medical attention. Taking into account that both the meanings of words and the cultural representations of emotions are very important to provide adequate medical attention, this paper addresses the emotion of anger and how it is related to health and illness. Accordingly, language itself, the cultural background of this emotion, and its impact on health are studied through a journey through contemporary medicine and its Hippocratic background, indigenous medicine, and modern medicine. For the population that took part in this study, the social representation of anger is linked to body heat balance, and therefore, from the point of view of men and women, some results are presented on the link between anger and health and disease. They conclude that there is a need for a cultural understanding of the diseases of Mexican people through the opportunities in the daily life of those who provide medical care.

Keywords

health; disease; Hispanic speakers; medical care; culture; anger
\end{abstract}

\section{Resumo}

0 presente exercício transdisciplinar apresenta a dificuldades que vivenciam os hispano-falantes legais ou ilegais que moram em outros países ao solicitar atenção médica. Levando em conta que tanto os significados das palavras quando as representações culturais das emoções são de grande importância para proporcionar a atenção médica adequada, este artigo aborda a emoção da fúria e sua relação com a saúde e a doença. De forma que a língua mesma e o conhecimento cultural sobre essa emoção e sua repercussão na saúde são estudadas mediante um percorrido pela medicina contemporânea e seus antecedentes hipocráticos, a medicina indígena e a medicina moderna. Para a população participante deste estudo, a representação social da fúria está relacionada com 0 equilíbrio térmico corporal, assim, desde o ponto de vista de homens e mulheres, apresentamos alguns resultados sobre a relação da fúria com a saúde e a doença. Estes evidenciam a necessidade de uma compreensão cultural sobre as doenças dos mexicanos através das oportunidades no dia-a-dia de aqueles que oferecem atenção médica.

\section{Palavras-chave}

saúde; doença; hispano-falantes; atenção médica; cultura; fúria 


\section{Introducción}

En esta época de tanto ir y venir entre personas de diferentes países, los índices de inmigración internacional -legal e ilegal- son cada vez mayores. Es evidente que en los medios de comunicación, en la política y en el mundo académico, el fenómeno de la inmigración es uno de los temas más discutidos. Entre las razones por tanta discusión y desacuerdo, en el fondo, podría estar el temor de que las culturas nacionales se vean sofocadas por una oleada de inmigrantes, especialmente cuando estos son de otro color de piel, religión o idioma.

Desde que llega un extranjero a un país nuevo existen distintos problemas a los que se tiene que enfrentar, empezando por uno de los más grandes: la comunicación. Aun cuando algunos inmigrantes saben o aprenden la lengua de su nuevo hogar, no siempre llegan a aprender ni a entender su cultura, o la asimilan de forma limitada. Para ellos, vivir entre dos mundos -el que traen con ellos y el nuevo donde llegan a vivir- puede resultar una situación peligrosa, sobre todo, en cuanto a la salud y la enfermedad.

En el caso del inmigrante y su familia, enfermarse y tener que buscar ayuda médica en su nuevo hogar puede volverse una tarea de suma importancia, y en algunos casos puede terminar en una situación de vida o muerte si la comunicación no es buena. La barrera del lenguaje entre pacientes y el personal médico puede ser un obstáculo serio para que el inmigrante reciba una atención médica satisfactoria.

En 2003, un estudio patrocinado por California Endowment y realizado por New California Media y Bendixen y Asociados (Marrero, 2003), reveló que, en California, a diferencia de lo que ocurría en el resto de Estados Unidos, la atención médica se había convertido en la principal preocupación para los inmigrantes de ese estado, superando a otros temas como educación o acceso a empleos, que continúan encabezando las listas de opinión pública en el resto de la nación. Un $36 \%$ de los inmigrantes latinos, un $42 \%$ de los vietnamitas, un $41 \%$ de los chinos, y significativos porcentajes de otros grupos inmigrantes, consideraban que la atención médica era el problema principal de California (Marrero, 2003).
Cuando dos o más pueblos con lengua y cultura distintas entran en contacto inmediato y continuo, ponen en marcha un conflicto de fuerzas entre modos de vida opuestos que produce, entre otras cosas, fenómenos de adaptación destinados a resolverse en una nueva organización social (Aguirre, 1994). El lenguaje médico en sí es bastante difícil de entender en la lengua materna, y tratar de entenderlo en una segunda lengua puede ser imposible. Este es un problema para muchos nuevos inmigrantes. Pueden recibir el cuidado físico que requieren, pero no necesariamente saben lo que está pasando durante una cita médica, o qué deben hacer después de su visita al médico.

Aunque hay profesionales en el área médica que entienden otra lengua (incluso la hablan), es difícil encontrar quién hable lenguas menos comunes. Algunos de estos profesionales saben bastante, o al menos lo suficiente para poder llevar una conversación básica con el paciente; pero sin una buena comprensión de la cultura del paciente, la comunicación puede crear confusión adicional. Para tener una conversación eficaz con un paciente, los profesionales en el área de la salud deben entender la cultura de su paciente y tener una idea de cómo esta afecta su lenguaje. Traducir directamente significados de palabras no es suficiente para que haya un entendimiento exitoso.

El hecho de que más de 14 millones de latinos norteamericanos no hablen inglés con fluidez, hace que la visita al doctor sea aún más desafiante. Una encuesta de opinión de la Commonwealth Foundation (Wallace et al., 2012) encontró que el $45 \%$ de los hispanos (de habla española) se quejan por problemas de comunicación cuando interactúan con sus médicos. Una cuarta parte de ellos reportaron que alguna vez han salido del consultorio sin que el médico les preguntara acerca de su salud, y la mitad de los encuestados reportaron dificultades para entender las recetas médicas.

Desde el punto de vista de los pacientes y especialistas, se señala que los profesionales angloamericanos suelen subestimar la relevancia cultural y las variables socioeconómicas que distinguen a los hispanos de los demás pacientes. Muchas veces los 
médicos y el personal que trabaja en el área de salud piensan que los pacientes latinos pueden llegar a entender y describir sus síntomas a través de los paradigmas culturales específicos de su cultura, como el mal de ojo o el desequilibrio espiritual; o síntomas atados a la cultura, ampliamente conocidos como ataques de nervios. No es sorprendente entender cómo una cuarta parte de los latinos encuestados opina que en su visita al especialista no fueron escuchados, o que les prestaron muy poca atención (Fadiman, 1998).

Con el propósito de invitar a la reflexión sobre la importancia de una enseñanza de lengua y cultura -en este caso del español y la cultura mexicana (y en particular de Puebla) - a profesionales en el área de salud de Estados Unidos, con la meta de mejorar las relaciones con sus pacientes mexicanos, tomamos el caso de la emoción del enojo y su significado en términos de salud y enfermedad como ejemplo para este trabajo. Consideramos que la enseñanza de lenguas para las personas que trabajan en el área de salud, en este estudio en Estados Unidos, debe ir más allá de enseñar a traducir palabras y expresiones, y debería incluir dentro de esta enseñanza un entendimiento tanto histórico como también antropológico, para atender a la enorme población mexicana que vive en Estados Unidos como son los que se encuentran en "Puebla York"1 (Nueva York), y en tantos otros lugares más de la unión americana. Se ha reconocido que si bien, en cada sociedad, los diferentes grupos usan formas específicas de atención tradicionales/populares, la mayoría de estas han dejado de ser patrimonio exclusivo de determinados sectores sociales, económicos o étnicos. Este proceso se ha intensificado en los últimos años, debido a las migraciones nacionales e internacionales, entre otros factores (Menéndez, 2005).

Los sentimientos y las emociones forman una parte innegable de los seres humanos. En mayor o menor grado, todos los individuos, sin excepción, han experimentado alegría, tristeza, amor $y$,

1 Una importante comunidad de poblanos, principalmente de la Mixteca, se ha establecido en Nueva York. De esta forma ha nacido el término Puebla York, que sirve para referirse a la comunidad migrante internacional de poblanos en Estados Unidos. por supuesto, enojo, y sus variantes -rabia, furia, coraje, mal humor o muina-. La experiencia de los sentimientos no solamente varía en intensidad sino también en motivos y razones por los cuales se desatan en los individuos; en ese sentido, su vivencia y expresión depende de factores como género y bagaje cultural.

En este artículo se aborda el enojo de acuerdo con el género y cómo los roles culturales aprendidos desde la infancia, según el grupo social en el que se haya crecido, influencian la manera de conceptualizar y representar tal sentimiento negativo. Debido entonces a que el enojo es diferente en cada individuo, ya sea por los motivos que lo desatan o por la forma como se exterioriza, es necesario explorar cómo cada uno de los géneros tiende a interpretarlos, así como las razones por las que se le asigna tal interpretación. Todo lo anterior con la finalidad de llegar a una comprensión mutua entre varones y mujeres, al no asignar falsos estereotipos o encasillarlos en papeles que les impidan expresar su sensibilidad.

\section{El enojo desde el punto de vista cultural}

Las diversas formas de atención a la enfermedad que actualmente operan en una sociedad, tienen que ver con las condiciones étnicas, religiosas, de género, económico-políticas, técnicas y científicas que han dado lugar al desarrollo y a formas diferenciadas de atención (Menéndez, 2005, p. 34). Se ha decidido estudiar, analizar y describir los aspectos y representaciones sociales del enojo en todas sus extensiones, ya que es parte importante y significativa en el mundo de creencias de los mexicanos, además esta emoción común los afecta debido a que es el modo que tienen de percibir su mundo y su entorno, es decir, las emociones negativas son vistas como agentes que tienen la capacidad de afectar la salud. Por eso, se explora este punto específico, ya que se ha visto que existen diferencias en cómo mexicanos y norteamericanos conciben, representan y significan dicha emoción negativa. 
El enojo desde el punto de vista cultural es una construcción histórica. Consciente o inconscientemente, aprendemos a reaccionar ante él, a sentirlo y a asignarle un valor. En ese sentido, las representaciones sociales que se le atribuyen a las emociones (en este caso al enojo), varían dependiendo del contexto cultural en el que nos encontremos y hayamos crecido, como lo menciona Catherine A. Lutz (citada por Palmer, 2000), "los conceptos de emoción están insertados en ricas redes pragmáticas y asociativas de significado y en consecuencia son eminentemente culturales" (p. 139). Al respecto, Renato Rosaldo (1991) comenta: "aun cuando parezcan subjetivos, el pensamiento y los sentimientos siempre se forman culturalmente y son influenciados por la biografía de la persona, situación social y contexto histórico" (p. 101). Es decir, las representaciones sociales del enojo que tiene la población urbana poblana subyacen en sus raíces, prácticas y creencias que se conectan con su pasado, pero que siguen siendo vigentes hasta nuestros días, ya que se expresan a través de los discursos médicos y cotidianos que existen entre ellos.

Lo arriba mencionado es demostrable a través de entrevistas a profundidad y cuestionarios abiertos y cerrados, los cuales son los instrumentos utilizados para alcanzar los objetivos de esta investigación. A través de ellos, se ha podido observar que: a) las cualidades frío y calor, en las cuales se basaba la medicina indígena, y la hipocrática occidental siguen vigentes; b) el enojo se siente en alguna parte del cuerpo; por ejemplo, el hígado, el estómago y la cabeza; c) el enojo perturba el equilibrio térmico del cuerpo, causando enfermedades como migraña, diabetes, derrame de bilis, cáncer; d) se consumen (pan salado) o se evitan (huevo y aguacate) alimentos después de haber experimentado enojo, lo anterior, con el fin de minimizar o evitar las consecuencias en el cuerpo.

Esto no significa que la población urbana poblana practique los sistemas de creencias médicas de los antiguos indígenas o como la medicina hipocrática occidental solía hacerlo; pero sí que dichos poblanos cuentan con el bagaje cultural que proviene de sus antepasados y que de una manera consciente o inconciente, echan mano de él al construir las representaciones sociales del enojo, es decir, al interpretarlo como agente de enfermedades y disturbio en el cuerpo.

\section{Enfermedad y salud desde el punto de vista cultural}

Tanto el sistema de creencia tradicional como el moderno científico buscan causas y soluciones a las enfermedades, sin embargo, el origen y las formas de abordarlas no se encuentran a la par. $\mathrm{Al}$ respecto, Faggetti (2004) menciona que "los sistemas médicos de los pueblos indígenas de México comparten una visión común de la enfermedad" (p. 13), en este caso los efectos que acarrean en el cuerpo y la salud las emociones (enojo/coraje/ira/rabia/muina/furia). Dicho sistema de salud no solamente tiene que ver con los pueblos indígenas sino también con la población urbana.

Existe una relación estrecha entre representaciones sociales, contexto, experiencias vividas y formas de expresar lo anterior, las cuales se manifiestan en el cuerpo u organismo, afectando asíla salud. La manera en que las personas abordan las diferentes situaciones a las que se encuentran expuestas se manifiestan, según Finkler (1994), en lesiones de vida:

Life's lessions are not fatal, as heart attacks or cancer are; rather they grind at the body and register on it non-lifethreatening symptomatologies. They intrude in the body in much the same way as any pathogen or anatomical lesion; they become fused with anatomical lesions and are felt as pain and suffering. (p. 19).

Es decir, si las lesiones de vida se manifiestan en el cuerpo, estas van a tener una razón diferente a las lesiones anatómicas. Así, por ejemplo, las emociones negativas (enojo/coraje/ira/rabia/ muina/furia) contenidas o prolongadas, causarán que el organismo se encuentre más vulnerable a las enfermedades. De acuerdo con las investigaciones realizadas por Fagetti (2004) en distintos pueblos indígenas de México, la bilis se puede derramar por emociones como el enojo y coraje, o por la ingesta de ciertos tipos de alimentos después de haberlas experimentado. 
Si bien, Finkler menciona que las lesiones de vida no ponen en riesgo la vida del que las padece, en los diferentes cuestionarios y entrevistas realizadas para esta investigación, se muestra que la población urbana poblana sí considera que las emociones (enojo/coraje/ $\mathrm{ira} / \mathrm{rabia} /$ muina/furia) pueden poner en riesgo la vida al relacionárseles como una de las causas de cáncer, además del derrame de la bilis mencionada por Faggeti. De lo cual resulta que el enojo se siente, se expresa y se representa de manera diferente con la propia cultura.

\section{Evolución de la medicina contemporánea}

Desde la antigüedad, el hombre ha tratado las enfermedades con la finalidad de buscar o restablecer la salud de sus pacientes, debido a que este ha sido siempre el objetivo de la medicina, sin importar el origen, ya sea indígena, occidental o científica moderna. Sin embargo, la búsqueda o el restablecimiento de la salud es algo que varía con el tiempo, lugar y tipo de médicos de los que se esté hablando. En este apartado se dará una breve descripción de cómo la medicina ha evolucionado con la finalidad de contrastar los diferentes sistemas de creencias y encontrar los rasgos sobresalientes que predominan en la cultura popular poblana con relación al enojo y su representación social.

\section{Antecedentes hipocráticos}

A su llegada a América, los españoles conquistadores trasladaron también sus sistemas de creencias sobre la enfermedad. En sus esquemas mentales cohabitaban desde las teorías humorales, hasta la religión, el maleficio, la adivinación y el deshechizamiento, como caminos terapéuticos para alcanzar el restablecimiento de la salud (Aguirre, 1992).

Desde los pitagóricos, el número cuatro gozaba de gran prestigio místico. Empédocles, Aristóteles y otros filósofos divulgaron que los elementos de la tierra eran cuatro. De acuerdo con esos principios, los médicos hipocráticos (500 a 400 años a.C.) descubrieron cuatro líquidos orgánicos fundamentales a partir de los cuales se atribuía la génesis y el mantenimiento de la vida: sangre, bilis, flema o linfa, bilis negra o atrabilis. Galeno, continuador de Hipócrates, sistematizó lo que había logrado la medicina durante seiscientos años atrás. Incluyó en sus escritos la numerología pitagórica, el sistema de los cuatro humores y de los cuatro estados de cuyo equilibrio dependía la salud. Los hipocráticos estaban convencidos de que la vida bullía en esos líquidos o humores del cuerpo y sobre la base de esos humores los hombres podían ser distribuidos en cuatro grupos o tipos, según predominara en ellos uno u otro de esos líquidos. Estos tipos eran: a) Sanguíneo, correspondiente al predominio de la sangre; en sus manifestaciones de carácter presentaban tendencia a la irreflexión, sociable, pero poco tenaz y persistente. b) Melancólico: predominaba lo que Hipócrates llamaba la bilis negra, se conocía también como tipo nervioso. c) Colérico: predominaba en su organismo la bilis amarilla. d) Flemático: predominaba la flema (Gaspar López, 1565).

Hipócrates y los demás médicos de su tiempo llamaban chole a cualquier humor del cuerpo humano que fuese amarillo, los poslatinos le llamaron bilis, y los médicos del siglo xvin le llamaron cólera. El color del cuerpo, sus acciones y los humores que de él se arrojan, eran los indicios de la buena o mala constitución de las partes principales, y aun del carácter propio y especial de la descompostura y desorden que en ellas se hallasen. Por las observaciones que se hacían se sabía que todos los humores se hallaban en la sangre bien mezclados, y con la proporción que a cada quien correspondía, según el destino de su naturaleza; debido a ello se creía que la cólera separada de las demás, solo se hallaba en la vejiga de la hiel (Piquer, 1757).

En términos contemporáneos, se puede afirmar que las características del colérico, enunciadas desde los planteamientos hipocráticos, son el enojo y la hostilidad. El colérico es extremadamente hostil. Algunos aprenden a controlar su ira, pero una erupción de violencia es siempre una posibilidad en ellos. No les lleva mucho tiempo comprobar que los demás, por lo general, se asustan de sus estallidos de enojo y de que por tanto pueden valerse de su ira como un arma para conseguir lo que quieren $-y$ generalmente lo que quieren es salirse con la suya-. 


\section{Medicina indígena}

Para los indígenas nahuas, las enfermedades se clasificaban en cualidades de frío y calor, las cuales deberían estar en equilibrio, de no ser así, se hablaba de un cuerpo enfermo, al que había que darle "alimentos o medicamentos de calidad contraria a la del mal para restablecer el orden" (López, 2000, p. 17). Foster (citado por López, 2000) argumenta que los conceptos de frío y calor de la medicina indígena se derivan de la medicina hipocrática de los humores. Sin embargo, López Austin difiere de ésta idea, pues para él: a) los inicios de la medicina indígena son más que nada hipotéticos, ya que no se tienen documentos de los que sea posible extraer información precisa de sus verdaderos orígenes; b) de ser así, se habría adoptado primero la teoría y después la práctica, y c) la polaridad frío/calor se referiría solamente a los aspectos relacionados con la salud, la enfermedad y la medicina, y no a todo el cosmos.

Al hombre, por supuesto, se le concebía también como un ser en equilibrio, por tanto, como individuo, él tenía que estar en la búsqueda constante de un balance, al contrarrestar factores, acciones o sucesos que pudieran alterarlo. Una de las maneras de alterar la armonía que debía guardar, estaba relacionada con la perturbación de los estados anímicos, los cuales eran estados físicos y, por tanto, se manifestaban en el cuerpo. "La ira provocaba una alteración de naturaleza caliente. Calentar, abrasar, hacer hervir o hinchar el corazón, eran sinónimos de embravecerse, encenderse de ira, enojarse" (p. 296). Es decir, para la medicina indígena, el estado de ánimo contribuye al cambio de temperatura. La ira provoca que el calor del cuerpo vaya hacia el exterior, así se aprecia en la apariencia física que se está experimentando la emoción negativa.

Es posible pensar que los estados y entidades anímicas derivan de la necesidad de dar una explicación a ciertos aspectos cotidianos que no se pueden explicar de otra manera. Sin embargo, a estos se les asignaban alteraciones fisiológicas reales. La ubicación de los estados y procesos anímicos se encontraban en tres órganos principales: a) corazón ( $y o l)$, b) cabeza/alma (incluso, mollera) (tonalli), c) hígado (elli).
El corazón $(y o l)$ era el órgano más importante, encargado de la vitalidad, el conocimiento y la afección; en él radicaban los atributos morales propios del sexo y todos los procesos anímicos. Se creía que el corazón se podía alterar para bien o para mal. Las causas externas que podían perturbarlo eran: tiempo, ofensas, hechizos, esclavitud. Y las interiores: ira y pecados.

En el hígado (elli) surge la energía del hombre, para hacer de este un ser "brioso, esforzado y valiente" (López, 2012, p. 209). En él se alojaban los sentimientos y pasiones que se consideraban alejadas de la función del conocimiento. El buen funcionamiento del elli se reflejaba en la persona que actuaba cautelosa y cuidadosamente. Por el contrario, de no funcionar correctamente, hacía del hombre un ser malvado y loco. Sin embargo, pese a su importancia como centro anímico, poco se decía de él. Se describía como ancho y grueso, tiene bordes, rojo, y se consideraba que era el recipiente de la sangre. Por otra parte, se ponía más atención a la hiel, que era descrita como espesa, verde y azul, causante de la ira de la gente. Esta atribución se ha considerado como producto de las observaciones de los trastornos biliares producidos por las fuertes alteraciones del ánimo (López, 2012).

La cabeza (tonalli) determinaba el valor o la fuerza que tendría el individuo; fuerza que se encontraba distribuida en todo el organismo, pero sus acciones curativas o preventivas estaban dirigidas a la mollera, cara, cabello o cabeza en general. El fortalecimiento o daño del tonalli provocaba la intervención de la divinidad suprema, ya fuese para premiar o para castigar.

Desde el punto de vista de la medicina indígena se puede decir que los sentimientos y las pasiones surgen en el corazón, pero que la manera de abordarlas dependerá de aquel que las está sintiendo. Si se llevan al conocimiento del bien y del mal, a un nivel de valoraciones morales y sociales, se estará echando mano de la cabeza. De no ser así, en caso de solo sentirlas y actuar, escoger el pecado y la maldad, entonces se estará usando el hígado. 
A través del tiempo, en el mundo mental indígena, el concepto de bilis se encuentra asociado a bilis derramada, coraje, enfermedad de enojo, muina, regada de bilis. El nombre más apropiado para este mal es derrame o regada de bilis, ya que la bilis se entiende como sinónimo de muina y también como un líquido existente en el cuerpo que, al derramarse, origina la enfermedad. Se ha creído también que la dolencia de la bilis es muy frecuente y que afecta a los adultos, sobre todo, a la mujer. Dado el lugar que ha ocupado en la sociedad, la mujer tiene menos posibilidades de exteriorizar o canalizar el enojo, y ello ocasiona que el coraje o la muina se queden en el cuerpo, mientras que el hombre puede hacerlo insultando o golpeando a los demás, evitando así que aquellos se acumulen en su interior y se origine la enfermedad. Una de las medidas preventivas más importantes, y cuya práctica se pierde en el pasado, es no consumir aguacate, leche o jitomate después de hacer coraje (experimentar emociones encontradas de rabia, enfado e irritación), ya que estos alimentos, por considerarse fríos, frente a la naturaleza caliente de la enfermedad, la desencadenarían (Mata, Méndez y Zurita, 1994).

Por otra parte, en la cosmogonía indígena frente a las enfermedades, no solo el enojo humano es causa de malestares físicos, el enojo de los dioses también podía desatarlos, y estos se manifestaban con la presencia de organismos extraños en el cuerpo. Las enfermedades materializadas en diversos objetos pequeños -navajas de pedernal, pedazos de papel, sabandijas-, eran extraídos por los curanderos a través de succiones orales o pellizcos. Tezcatlipoca, el dios hechicero, era directamente señalado como el ente responsable de esas alteraciones (Aguirre, 1994).

\section{Medicina moderna}

Después del año 1750, la medicina moderna clínica adquiere auge, aunque la observación del cuerpo humano empieza antes del siglo xvi. El primer objeto de estudio es el "cuerpo humano formado por órganos, tejidos y células" (Fauré, 2005, p. 24), $y$ en segundo lugar el entorno en el que el enfermo se encuentra inmerso, de lo cual se cree que la medicina moderna viene o está fundada en las dos ideas antes mencionadas. Sin embargo, la visión fisiológica y localista es la que destaca y adquiere mayor importancia. Aunque la medicina especializada surge como consecuencia de la búsqueda de mejores tratamientos y mayor conocimiento del organismo humano, ha sido ampliamente criticada desde hace un par de siglos, por el hecho de dejar de lado a la persona y convertir un órgano o una disfunción en su objeto de estudio, es decir, en este tipo de medicina, solamente se enfoca una parte del ser humano fuera de su contexto en donde sus experiencias vividas no son tampoco de importancia alguna (Fauré, 2005, p. 25).

Alrededor de la misma época se fundan los primeros hospitales clínicos, en donde la atención está no solamente puesta en la enseñanza clínica, sino también en la observación de los pacientes que ahí son tratados. La apertura de hospitales para indigentes brinda a los médicos cuerpos a su disposición. Tanto los cuerpos vivos como los muertos, se vuelven importantes en la medicina. A través de la autopsia se pueden llegar a conocer "los efectos ocultos de la enfermedad y ayudar a su comprensión" (Fauré, 2005, p. 26). La anatomía clínica es entonces, la relación entre la observación de los síntomas de los enfermos y la anatomía patológica.

Para este sistema médico ni el entorno de los pacientes ni sus experiencias vividas son suficientemente importantes para tomar en cuenta en el momento de diagnosticar una enfermedad o de recetar algún medicamento. Para ellos, las enfermedades son una ecuación matemática, en donde lo que se sigue conservando de la antigüedad es solamente la observación de los síntomas, pero no el contexto en el que lo enfermos se desenvuelven.

Hacia los años de 1830, el programa de los fisiólogos se basaba más en convicciones profundas que en pruebas que se pudieran aportar. Pero fue a partir de las experiencias de Claude Bernard sobre los efectos del curare y sobre la función glucogénica del hígado, cuando se apuntan definiciones generales y revolucionarias sobre el organismo y la enfermedad. En la fabricación de azúcar por el hígado, la transformación del glucógeno en azúcar, 
corresponderá a los fenómenos de destrucción orgánica puramente químicos, mientras que la creación de glucógeno es "un acto vital cuyo origen esencial desconocemos todavía" (Fauré, 2005, p. 45). Las investigaciones posteriores a Bernard, incluidos sus trabajos, estuvieron también apoyadas en el concepto de bilis como sustancia asociada al funcionamiento del hígado. Sin embargo, de acuerdo con Gadamer (1996), no es posible tratar una enfermedad tomando en cuenta solamente una parte de esta. Cuando se quiere llegar a la cura es necesario tratar al paciente en su totalidad, no hay que separar el cuerpo del alma, es decir es necesario adoptar una visión holística.

\section{La relación del enojo con la salud y la enfermedad hoy en día}

La representación social del enojo en la población urbana poblana parece tener diferentes y muy característicos rasgos que provienen tanto de la medicina náhuatl como de la hipocrática al mismo tiempo. Primeramente, se debe definir lo que la palabra enojo significa: movimiento del ánimo, de acuerdo con la Real Academia Española (2014); ánimo, viene del latín y significa alma (Lexipedia, 2002). Como se recordará, tanto la idea de ánimo como alma provienen de las representaciones sociales que tenían los antiguos nahuas. Para ellos, la concepción de lo anímico es una unidad estructurada con capacidad de independencia, es decir, es un agente volitivo. Lo cual resulta traslaparse a la representación social que la población urbana poblana tiene del enojo. Para estos, el enojo es visto también como un agente capaz de causar enfermedades en el cuerpo.

En segundo lugar, en la representación social del enojo de la población estudiada, se refleja al mismo tiempo la idea de equilibrio térmico, el cual es alterado al enojarse. Este aspecto de armonía se encontraba presente tanto en la medicina náhuatl como en la hipocrática occidental. Para ambas creencias, el cuerpo debía guardar un equilibrio térmico, de no ser así, se le consideraba como un cuerpo enfermo. Tercer punto, el enojo se siente $y$ afecta diferentes partes del cuerpo, como: el estómago, la cabeza, y muy importante el hígado (elli). Ha de recordarse que en el sistema médico náhuatl era el hígado donde se sentía la ira, pero, el corazón donde esta se originaba. Cuarto y último punto de comparación que se ha encontrado hasta el momento, es la comida y las bebidas que se aconseja comer y no comer. A las cuales se les asigna cualidades frías o calientes, por lo cual hay que tener cuidado al ingerirlas después de haber alterado el equilibrio térmico a razón del enojo.

\section{Palabras y significados detrás del enojo}

Las palabras a diario utilizadas conllevan diferentes significados dependiendo de la situación, el momento y el género que haga uso de ellas, como lo menciona Frawley (1992), "language is a product of our mental system" (p. xII). Si se quiere entender y comprender lo que el sexo opuesto está expresando, es necesario, entonces, entender también el contexto en que cada individuo se desenvuelve.

El enojo es uno de los rubros a mencionar al referirse a las emociones negativas. Este no es característico ni exclusivo de mujeres o varones, y aunque ha sido experimentado por todos los seres humanos, sin importar sexo o edad, la manera que tiene cada uno de ellos de expresarlo difiere en gran medida; de acuerdo con Shapiro (1993), "no es el hecho en cuestión la causa de nuestra respuesta, sino nuestra propia reacción ante el acontecimiento" (p. 13). Es decir, las reacciones a las emociones negativas son aprendidas y estas pueden ser el resultado de valorizaciones morales, sociales, religiosas y a veces hasta políticas.

Mientras que el enojo es el único sentimiento que los varones tienen socialmente permitido exteriorizar, de las mujeres se espera que lo puedan controlar, esconder o reprimir, de lo contrario son señaladas o juzgadas por la sociedad en la que se desenvuelven. "Los hombres somos socializados en la lógica de la guerra; en esa lógica quien expresa sus emociones, a excepción de la rabia, refleja debilidad, pues muestra una sensibilidad que lo pone en peligro ante posibles enemigos" (Luco, 2001, p. 87). Es decir, el varón tiene que mostrar su fortaleza y 
fuerza ante todo, no es posible doblegarse y darse el lujo de sentir y demostrar ningún otro tipo de sentimiento más que el enojo, ya que este el que se puede transmitir mediante expresiones físicas y con rudeza, pues para eso son hombres. A los hombres, no se les permite mostrar ningún indicio de debilidad, son el sexo fuerte, por lo que se les dificulta más vivir su sensibilidad. Desde pequeños se les enseña a no llorar. "Una niña que llora suscita comprensión y cariño; si el niño llora, se le acusa de 'gallina"' (Hartog, 2001, p. 94).

Los roles sociales que marca cada una de las culturas o grupos en los que los individuos se desarrollan y crecen, están íntimamente ligados con cómo estos tienen de comportarse y de reaccionar ante las situaciones cotidianas de su vida. Lo cual se puede observar a través de las palabras y expresiones que varones y mujeres usan, respectivamente, al dirigirse al enojo y su manera de abordarlo.

\section{Instrumento}

El instrumento implementado en este estudio fue un cuestionario, resultado de diferentes y diversas pruebas piloto relacionadas con el enojo. Cada cuestionario ha mostrado las diferentes maneras en las que, tanto varones como mujeres, se desenvuelven con respecto al enojo, así como su expresión $\mathrm{y}$ vivencia, a través de las palabras utilizadas para referirse a él. Los participantes con los que contó esta investigación fueron 80 jóvenes universitarios(as) poblanos(as), de entre 18 a 21 años, quienes se encuentran estudiando en una universidad privada en la capital del estado de Puebla (México) y con quienes se ha establecido una relación de docente con una de las autoras del presente trabajo. El grupo encuestado comprendió 40 mujeres y 40 hombres, todos estudiantes, como se ha señalado.

El cuestionario utilizado en este estudio contiene tres partes principales: a) los datos sociodemográficos, b) las preguntas abiertas y c) las preguntas cerradas. Debido a que este es un estudio comparativo en donde se busca conocer si existen diferencias o similitudes en la manera en la que varones y mujeres interpretan el enojo a través del lenguaje, la única variable independiente que se consideró fue el sexo de los participantes, lo cual permite identificar cómo se ancla la representación social del enojo a través de la construcción social del género femenino y masculino. Por otro lado, el preguntar la edad y la ocupación de los participantes responde a la delimitación del propio estudio.

En la segunda parte del cuestionario se elaboraron preguntas abiertas, las cuales permiten identificar y explorar las diferentes actitudes y opiniones relacionadas al enojo y la manera en cómo es representado o expresado entre mujeres y varones. Las razones por las cuales cada uno de los géneros tiende a enojarse, el lugar del cuerpo en donde se percibe o siente la emoción negativa y los aspectos positivos y negativos al dejarlo fluir. El objetivo de esta sección es permitir a los(as) participantes describir en sus propias palabras, y sin influencia alguna, su representación social del enojo. Por lo anterior, se colocaron estratégicamente en el cuestionario las preguntas abiertas antes que las preguntas cerradas, con el fin de evitar que el contenido de estas últimas influyera en las preguntas abiertas.

En la tercera y última parte del cuestionario, se incluyeron preguntas cerradas, las cuales fueron divididas en cinco secciones, y donde en cada una se buscaba comparar las respuestas del género femenino y masculino. Se decidió incluir ciertas enfermedades, ya que estas fueron mencionadas en las respuestas a los cuestionarios piloto como resultado del enojo, por ejemplo: cáncer, problemas de hígado, colitis, migraña, entre otras. Una segunda razón para que estas enfermedades sean significativas en esta investigación es que son las mismas con las que la medicina náhuatl e hipocrática asocian como consecuencia del enojo. Las respuestas a estas preguntas mostraron la relación enojo/enfermedad, la cual parece existir sobre todo en las jóvenes universitarias participantes en este estudio.

También, se tomó en cuenta para el cuestionario que cierto tipo de alimentos como huevos, aguacate y comida condimentada, se evita después de haber experimentado el enojo pues se cree que estos alimentos ayudarán a desatar los posibles futuros malestares 
o enfermedades fruto del enojo. Por su parte, el consumo de bebidas dulces, así como pan dulce, se considera igualmente dañino después del enojo.

Se decidió incluir siete opciones de actividades al experimentar la emoción negativa en el cuestionario, para explorar la forma como las actividades a seguir después del enojo varían o coinciden, dependiendo del sexo del individuo. Otra pregunta cerrada que se incluyó se elaboró con el propósito de conocer las razones por las que cada uno de los géneros se enoja, además de saber cómo cada uno de estos percibe al género opuesto. Las tres últimas preguntas se circunscribieron para conocer el papel que la cultura desempeña dentro de la interpretación social del enojo, para cada uno de los géneros.

\section{Algunos resultados}

La diferencia en las palabras y frases que tanto varones como mujeres han utilizado para referirse al enojo muestra cómo se educa a cada género, así como lo que la sociedad acepta y rechaza en relación a sus actitudes y forma de expresar sus sentimientos. Mientras al género femenino se le permite estar en contacto con su sensibilidad y emociones (tristeza, alegría, amor), a través de la experiencia y expresión de ellos, al género masculino se le juzga y señala en caso de mostrar sentimientos que se asocian al género femenino.

Los resultados obtenidos a través de este cuestionario muestran que para el $58 \%$ de las mujeres, el enojo es caracterizado principalmente como un sentimiento o una emoción, mientras que para los varones las palabras sentimiento o emoción parecen no existir dentro de su vocabulario, ya que solo el $1 \%$ hace referencia a ellas. Las mujeres, a su vez, se refieren al enojo como "un sentimiento que a veces no se puede evitar", lo cual demuestra que ellas están conscientes de que el enojo no es algo que la sociedad les permita mostrar, sino más bien deben reprimirlo y esconderlo; de no ser así se les podrían asignar falsos estereotipos.

Por su parte, el $25 \%$ de los varones, quienes buscan tener el control no solamente de la situación que ellos están experimentando, sino también de las de los otros, manifiestan que el enojo es una "reacción que no se puede controlar". Así, a través de frases como estas, podemos darnos cuenta de que el enojo para los varones es acción/reacción o algo incontrolable y esperado, como la reacción a una alergia o gripe. $\mathrm{Al}$ ser el enojo visto como una reacción, el $68 \%$ de los hombres consideran que es mejor sacarlo y deshacerse de él en el momento, ya que en caso de no expresarlo y exteriorizarlo podría causarles enfermedades o malestares en su cuerpo, como: estrés, dolor de estómago, dolor de cabeza y hasta cáncer.

Los varones han mencionado también que el enojo "se puede transmitir", lo cual indica que para ellos es una enfermedad sobre la cual el individuo no tiene control alguno, es decir, se ve más bien como un agente capaz de afectar al organismo en el que se aloja, por lo que es necesario deshacerse de él al exteriorizarlo. Por su parte, $45 \%$ de las mujeres consideran que las enfermedades que causan el enojo se desatan una vez que este se expresa o se exterioriza. Por lo cual prefieren o "tienen" que guardarlo dentro de sí. Las enfermedades que la manifestación o expresión del enojo pueden desatar van no solamente desde una migraña, problemas de hígado y hasta cáncer, sino que se extienden mucho más allá de los malestares físicos, es decir, a un nivel social y cultural. Cabe recordar que el rol de la mujer es el de cuidadora y protectora, alguien que entiende y escucha, por lo cual tiene siempre que estar dispuesta en su rol, hasta el grado de reprimir sus propios deseos y sentimientos, y pensar en los que la rodean antes que en ella.

De acuerdo con el $58 \%$ de las mujeres encuestadas, los aspectos negativos al manifestar el enojo se ven reflejados a través de la agresión verbal, ya que se corre el riesgo de "hacer comentarios bruscos", lo cual, el género femenino no se puede dar el lujo de hacer, ya que que se debe guardar la compostura y encontrar las palabras correctas para cada situación. $\mathrm{Al}$ respecto, el $23 \%$ de las respuestas de los varones revelan que ellos ven también, como aspecto negativo del enojo, el "ofender" así como la "agresión física”. Sin embargo, debido a que a los varones se les da la oportunidad de "explotar" y de "desahogar sus 
frustraciones", es decir, socialmente no es mal visto ni se juzga ver a un hombre enojado, estos no tienen problemas al reaccionar ante el enojo de tal manera.

Por lo anterior, el $35 \%$ de los varones no encuentran problema al manifestar que para ellos el enojo es "algo normal o común en su vida", además de aceptar que a veces tiene causas internas. En cuanto al género femenino, para el $50 \%$, la responsabilidad de su enojo recae, sobre todo, en terceros, situación que una vez más pone de manifiesto su rol. Si el enojo es "algo que vuelve desagradable a las personas", y si ya se mencionó que no es bien visto por la sociedad en la que se desenvuelven, ¿cómo se podría aceptar que las causas de ese enojo son propias o internas? Una vez más, no sería bien visto y correrían el riesgo de que se les juzgue o se les asignen falsos estereotipos.

A través de los resultados encontrados en esta investigación, se concluye que la manera de vivir, interpretar y expresar el enojo está íntimamente ligada al género al que se pertenece, el cual se va construyendo desde el momento en que se nace hasta que conscientemente el individuo adquiere un sentido de pertenencia en la sociedad o grupo en el que vive.

De lo cual resulta que los varones, tal vez inconscientemente y debido a su bagaje cultural, querrán resolver la causa que ha desatado el enojo de sus allegados. Y las mujeres, por su parte, querrán hacer a sus interlocutores hablar, para desahogarse de lo que provocó su enojo y así sobreponerse de él. Una vez que varones y mujeres entiendan cómo cada uno de ellos tiene permitido vivir y expresar su enojo, llegarán a una mejor comprensión y entendimiento entre ambos, con lo cual podrán también ver el mundo desde una perspectiva diferente.

\section{Conclusión}

Entender, interpretar y reconocer las diferentes enfermedades más representativas dentro de la cultura mexicana, en general, es importante para quienes trabajan en el área de salud. Cada año, México es visitado por alumnos de premedicina, medicina, médicos, enfermeras y otros profesionales de la salud, que acuden a cursos en la búsqueda de oportunidades de aprender sobre la vida cotidiana, vocabulario y cultura, para poder acercarse mejor a sus pacientes mexicanos en Estados Unidos. Con un entendimiento más claro de cómo el inmigrante interpreta y conceptualiza su cuerpo, la enfermedad y la salud, además de comprender lo que ellos esperan dentro de la consulta médica y en el tratamiento de una enfermedad, es importante estudiar la cultura y el papel que cumplen las emociones dentro de su visión de salud. Así, una mayor comprensión puede resultar en un mejor trato médico de la enfermedad, más exitoso y con un ahorro en los gastos, tanto del paciente como también del estado. En algunos casos se podría ahorrar en intervenciones médicas y en el uso de medicinas, entre otras cosas, si existiera una mejor comunicación entre el personal médico y el paciente que condujera a entender las prácticas culturales.

\section{Referencias}

Aguirre, G.B. (1992). Medicina y magia. El proceso de aculturación en la estructura colonial. México: Universidad Veracruzana, Instituto Nacional Indigenista, Gobierno del estado de Veracruz y Fondo de Cultura Económica.

Aguirre, G.B. (1994). Antropología médica. México: Universidad Veracuzana, Instituto Nacional Indigenista, Gobierno del Estado de Veracruz y Fondo de Cultura Económica.

Fadiman, A. (1998). The spirit catches you and you fall down: A Hmong Child, her American doctors, and the collision of two cultures. Estados Unidos: Farrar, Straus \& Giroux.

Fagetti, A. (2004). Síndromes de filiación cultural; conocimiento y prácticas de los médicos tradicionales en 5 hospitales integrales con medicina tradicional del estado de Puebla. México: Intergraf.

Fauré, O. (2005). La mirada de los médicos. En A. Corbin (dir.), Historia del cuerpo. De la Revolución francesa a la gran guerra (pp. 23-56). Madrid: Taurus.

Finkler, K. (1994). Women in pain. gender and morbidity in Mexico. Philadelphia, , Estados Unidos: Universidad de Pensilvania Press.

Frawley, W. (1992). Linguistics Semantics. Nueva Jersey, Estados Unidos: Lawrence Erlbaum Associates Inc.

Gadamer, H.G. (1996). El estado oculto de la salud. Barcelona: Gedisa. 
Gaspar López, G.C. (1565). In libros Galeni De temperamentis noui et integri commentarii... Alcalá de Henares: Compluti apud Petrum Robles \& Franciscum Cormellas.

Hartog, G. (2001). Socialización y cambios a favor de una verdadera igualdad de género. Sociotam Revista Internacional de Ciencias Sociales y Humanidades, XI(2), 83-107. Recuperado de http://biblat.unam. $\mathrm{mx} / \mathrm{es} /$ revista/sociotam-revista-internacional-deciencias-sociales-y-humanidades/10

Lexipedia (2002). Enojo. Recuperado de http://www. lexipedia.com/spanish/enojo

López, A.A. (2000). Textos de medicina náhuatl. Ciudad de México: Universidad Nacional Autónoma de México.

López, A.A. (2012). Cuerpo humano e ideología. Las concepciones de los antiguos nahuas. Ciudad de México: Instituto de Investigaciones Antropológicas y Universidad Nacional Autónoma de México.

Luco, A. (2001). El sexo imaginario. En J. Olavarría (ed.) Hombres: Identidad/es violencia (pp. 85-90). Santiago de Chile: FLACso.

Marrero, P. (17 de julio de 2003). La barrera de la lengua hace peligrar la salud. La Opinión. Recuperado de http://www.um.es/tonosdigital/znum6/Recortes/ Barrera.htm
Mata, S.P., Méndez, D.G. y Zurita, M.E. (1994). Diccionario enciclopédico de la medicina tradicional mexicana. Ciudad de México: Instituto Nacional Indigenista.

Menéndez, E.L. (2005). Intencionalidad, experiencia y función: la articulación de los saberes médicos. Revista de Antropología Social, 14(2005), 33-69. Recuperado de http://www.redalyc.org/articulo. oa?id=83801402

Palmer, G.B. (2000). Lingüística cultural. Madrid: Alianza.

Piquer, A. (1757). Las obras de Hipócrates más selectas. Madrid: Joachin Ibarra.

Real Academia Española (2014). Diccionario de la lengua española. 23a. ed. Recuperado de http://dle.rae.es/ srv/fetch?id=FXaHNmt

Rosaldo, R. (1991). Cultura y verdad. Ciudad de México: Grijalbo.

Shapiro, D. (1993). Cuerpo mente. La conexión curativa. México: Robin Book.

Wallace S.P., Torres, J., Sadegh-Nabori, T., Pourat, N. y Brown, E.R. (2012). Undocumented Immigrants and Health Care Reform. Recuperado de http://healthpolicy.ucla.edu/publications/Documents/PDF/ undocumentedreport-aug2013.pdf 